\title{
A Magnetization Study of Prussian-blue Analogue $\mathrm{Na}_{\mathrm{x}} \mathrm{Mn}$ y $\left[\mathrm{Fe}(\mathrm{CN})_{6}\right]$
}

\author{
Nguyen Van Minh ${ }^{1}$, Phung Kim Phu', Nguyen Minh Thuan ${ }^{1}$, and In-Sang Yang ${ }^{2 *}$ \\ ${ }^{1}$ Center of Nano Science and Technology, Hanoi National University of Education, 136 Xuan-Thuy Rd., Hanoi, Vietnam \\ ${ }^{2}$ Department of Physics and Division of Nano-Sciences, Ewha Womans University, Seoul 120-750, Korea
}

(Received 21 November 2008, Received in final form 1 December 2008, Accepted 2 December 2008)

\begin{abstract}
In this report, we present the results of a study on the effects of the particle size on the properties of the Prussian blue (PB) analog $\mathrm{Na}_{\mathrm{x}} \mathrm{Mn} \mathrm{n}_{\mathrm{y}}\left[\mathrm{Fe}(\mathrm{CN})_{6}\right]$. A novel synthesis method of the $\mathrm{Na}_{\mathrm{x}} \mathrm{Mn} \mathrm{n}_{\mathrm{y}}\left[\mathrm{Fe}(\mathrm{CN})_{6}\right]$ nano-particles using an organic solvent, formamide, is employed. The size of the PB particles is found to be $100-150 \mathrm{~nm}$ for the samples prepared in the formamide solvent, which is much smaller than that of the samples prepared using water only. The broadening of the X-ray diffraction peaks of the nano-sized PB samples is attributed to the lattice disorder and a dramatic reduction in the particle size. The compositions of the samples are confirmed by an energy-dispersive $X$-ray analysis (EDAX), and the result proves that the samples are actually $\mathrm{Na}_{\mathrm{x}} \mathrm{Mn} \mathrm{n}_{\mathrm{y}}\left[\mathrm{Fe}(\mathrm{CN})_{6}\right]$ Prussian blue. The UV-vis spectra show a broad intervalence charge-transfer $(\mathrm{CT})$ band in the visible region between 400 and $700 \mathrm{~nm}$, and the absorption decreases abruptly in the green region for the nano-sized PB sample. A divergence between the field cooled (FC) and zero field cooled (ZFC) magnetization curves is observed for the nano-sized PB sample at $11 \mathrm{~K}$, indicating that nanoparticles in the sample are single domain superparamagnets with a blocking temperature of $11 \mathrm{~K}$. Our results reveal that the nano-sized PB samples show significantly different optical and magnetic properties than those of the bulk PB samples.
\end{abstract}

Keywords : Prussian blue, nanoparticles, magnetization

\section{Introduction}

Magnetic properties of nano-sized particles are known to be different from those of bulk material. $\mathrm{Ag}[1], \mathrm{CuNi}$ [2], and Fe [3] are a few examples. Prussian Blue (PB) and its analogues form an important class of insoluble, mixed-valence compounds, and have applications in magnetic materials [4, 5], molecular sieves [6], catalysis, solid state batteries, biosensors [7] and molecular magnets [8]. However, research activities on Prussian blue analogues have focused mainly on the properties of their bulk forms. In recent years, nano-sized Prussian blue analogues have emerged as a promising subject for applications to nanomagnetic devices $[4,5]$. These materials often exhibit novel size-dependent properties which show different properties from their bulk forms [9]. Several techniques have been suggested for preparing such nano-sized materials. Here, we present another new approach for the growing nanoparticles of cyano-bridged molecule-based magnets using an organic solvent, formamide. $\mathrm{Na}_{x} \mathrm{Mn}_{y}\left[\mathrm{Fe}(\mathrm{CN})_{6}\right]$ nano-

\footnotetext{
*Corresponding author: Tel: +82-2-3277-2332
}

Fax: +82-2-3277-2372, e-mail: yang@ewha.ac.kr particles (denoted $\mathrm{Mn}-\mathrm{Fe}$ ) were successfully synthesized in a formamide-water mixture and their particle sizes were controlled by varying the ratio between formamide and water. In addition, we investigate the structural, magnetic and optical absorption properties of size-controlled Mn-Fe nanoparticles.

\section{Experiment}

The synthesis of $\mathrm{Na}_{x} \mathrm{Mn}_{y}\left[\mathrm{Fe}(\mathrm{CN})_{6}\right]$ samples has been carried out by a route similar to that described in Ref. [9] with some modifications. $\mathrm{NaCl}, \mathrm{MnCl}_{2}$, and $\mathrm{K}_{3}\left[\mathrm{Fe}(\mathrm{CN})_{6}\right]$ as a starting mixture, were used as the precursors. The particle size of $\mathrm{Na}_{x} \mathrm{Mn}_{y}\left[\mathrm{Fe}(\mathrm{CN})_{6}\right]$ was found to be dependent on the ratio of formamide content to water content. Thus the particle size was controlled by varying the formamide-water ratio. In this report, two different types of samples are compared; the first type is made using water solvent only, hereafter called the "water" sample, and the second type is made using formamide solvent only, hereafter called the "formamide" sample.

Structural characterization was performed by means of X-ray diffraction using a D5005 diffractometer with $\mathrm{Cu}$ 
$\mathrm{K} \alpha$ radiation. FE-SEM was operated by using a S4800 (Hitachi) microscope. Optical absorption spectra, while disregarding reflection losses, were measured with a V670 spectrophotometer (Jasco) in the wavelength range of 190 to $800 \mathrm{~nm}$ at room temperature. The magnetic properties of the samples were investigated by using a magnetic property measurement system, the PPMS 6000 (Quantum Design).

\section{Results and Discussion}

Fig. 1 shows the typical field-emission scanning electron microscopy (FE-SEM) images of the samples. From the images we can see that the $\mathrm{Na}_{x} \mathrm{Mn}_{y}\left[\mathrm{Fe}(\mathrm{CN})_{6}\right]$ particles are of a cubic shape with an average size of about $2 \mu \mathrm{m}$ for the "water" sample (a), and 100-150 nm for the "formamide" sample (b). Clearly, the size of the $\mathrm{Na}_{x} \mathrm{Mn}_{y}$ $\left[\mathrm{Fe}(\mathrm{CN})_{6}\right]$ particles synthesized using formamide solvent only is much smaller than that of the particles synthesized using water only as a solvent. This indicates that the formamide solvent has prevented the growth of the $\mathrm{Na}_{x} \mathrm{Mn}_{y}\left[\mathrm{Fe}(\mathrm{CN})_{6}\right]$ particles.

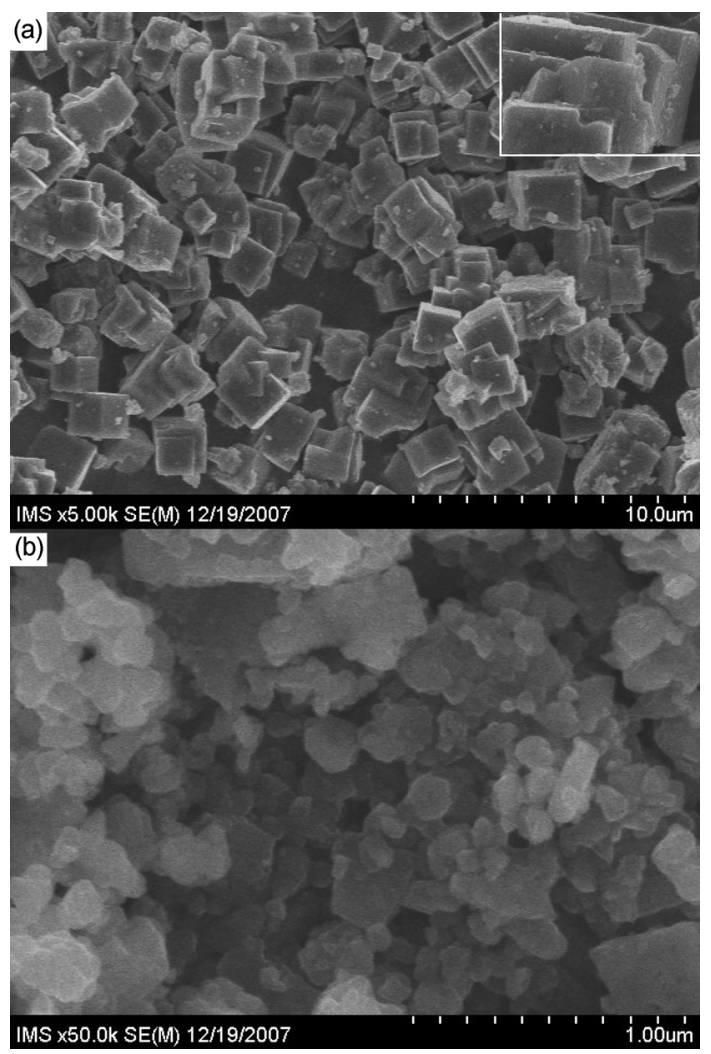

Fig. 1. Typical field-emission scanning electron microscopy (FE-SEM) images of the $\mathrm{Na}_{x} \mathrm{Mn}_{y}\left[\mathrm{Fe}(\mathrm{CN})_{6}\right]$ particles: synthesized using the (a) water and (b) formamide solvent. The enlargement in the upper right-hand corner provides a clear view of the crystal shape.
The powder X-ray diffraction patterns of the samples are shown in Fig. 2. All of the diffraction peaks are readily indexed to a pure face centered cubic (fcc) phase [space group Fm3m (no.225)] [10] with a lattice constant of $\mathrm{a}=10.37 \AA$, and no other impurity phases were found. The broadening of the X-ray diffraction peaks of the "formamide" samples is attributed to the lattice disorder and a dramatic reduction in the particle size.

The compositions of the samples are confirmed by an energy-dispersive X-ray analysis (EDAX), which reveals the presence of carbon, nitrogen, oxygen, iron, manganium, sodium and potassium. Fig. 3 and Table 1 show data for the "formamide" sample, which is almost the same as the data for the "water" sample. It is not possible to exactly determine the $\mathrm{x}$ and $\mathrm{y}$ values in the formula $\mathrm{Na}_{\mathrm{x}} \mathrm{Mn}_{\mathrm{y}}$ $\left[\mathrm{Fe}(\mathrm{CN})_{6}\right]$ from EDAX. Moreover, there are small amounts of potassium impurities in the samples, because the potassium elements, which were introduced from the starting

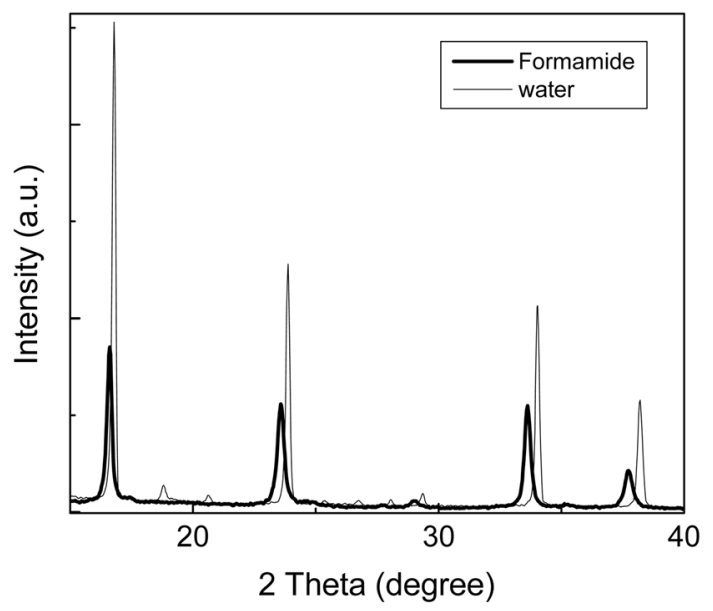

Fig. 2. Powder X-ray diffraction patterns of the two samples. The pattern corresponds to the space group Fm3m (no.225).

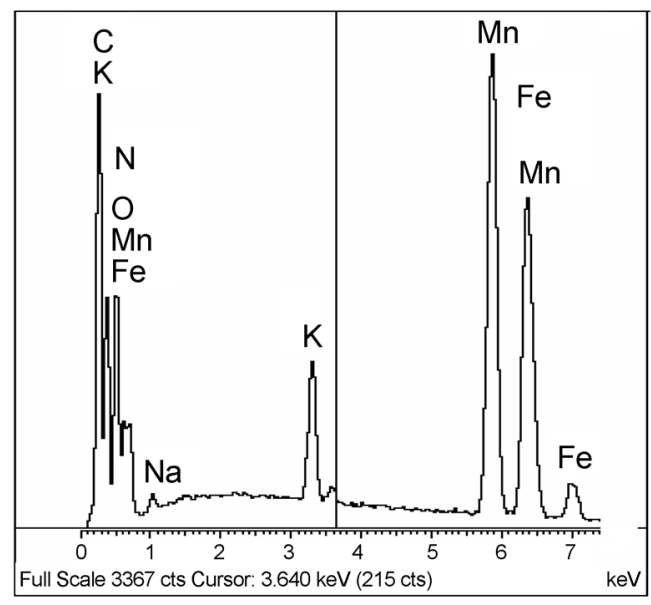

Fig. 3. EDAX of $\mathrm{Na}_{x} \mathrm{Mn}_{y}\left[\mathrm{Fe}(\mathrm{CN})_{6}\right]$ sample synthesized using the formamide solvent. 
Table 1. Compositions of $\mathrm{Na}_{x} \mathrm{Mn}_{y}\left[\mathrm{Fe}(\mathrm{CN})_{6}\right]$ sample synthesized using the formamide solvent.

\begin{tabular}{ccc}
\hline \hline Element & Weight\% & Atomic\% \\
\hline $\mathrm{C}$ & 25.47 & 36.00 \\
$\mathrm{~N}$ & 30.25 & 36.66 \\
$\mathrm{O}$ & 17.74 & 18.82 \\
$\mathrm{Na}$ & 0.36 & 0.26 \\
$\mathrm{~K}$ & 1.67 & 0.73 \\
$\mathrm{Mn}$ & 13.40 & 4.14 \\
$\mathrm{Fe}$ & 11.12 & 3.38 \\
Total & 100.00 & 100.00 \\
\hline
\end{tabular}

material $\mathrm{K}_{3}\left[\mathrm{Fe}(\mathrm{CN})_{6}\right]$, were not completely washed out by water or ethanol. However, the EDAX result proves that both of the samples are actually $\mathrm{Na}_{\mathrm{x}} \mathrm{Mn}_{\mathrm{y}}\left[\mathrm{Fe}(\mathrm{CN})_{6}\right]$ Prussian blue, although their morphologies are quite different from each other.

The UV-vis spectra of both samples are shown in Fig. 4. Both of the spectra have a broad intervalence chargetransfer (CT) band in the visible region between 400 and $700 \mathrm{~nm}$. The band structure calculation also suggests that the absorption corresponds to the $\mathrm{CT}$ from $\mathrm{Mn}^{\mathrm{II}}$ to $\mathrm{Fe}^{\mathrm{III}}$ [11]. Both of the compounds have broad absorption peaks at around $320 \mathrm{~nm}$ and $440 \mathrm{~nm}$. However, it is interesting to note that there is a difference between the two samples in the shape of the spectra; the absorption decreases abruptly in the green region for the small particle "formamide" sample. The absorption peaks of the nano-sized particle sample ("formamide") are sharper than those of the bulk form ("water" sample), which can be understood based on the selection rules [12].

Fig. 5 shows the zero-field-cooled (ZFC) and fieldcooled (FC) magnetization curves in the range of 2-50 K, obtained for both of the $\mathrm{Na}_{x} \mathrm{Mn}_{y}\left[\mathrm{Fe}(\mathrm{CN})_{6}\right]$ samples. The FC and ZFC of the "water" sample overlap each other

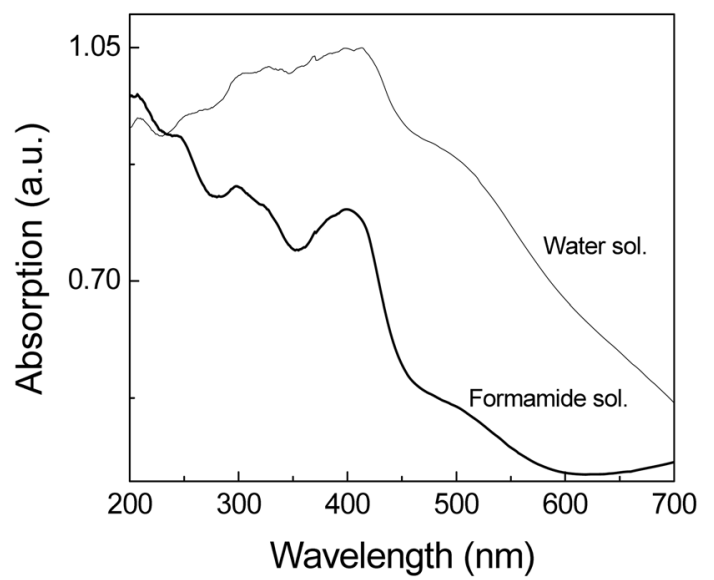

Fig. 4. Absorption of the samples synthesized using the (a) water and (b) formamide solvent.

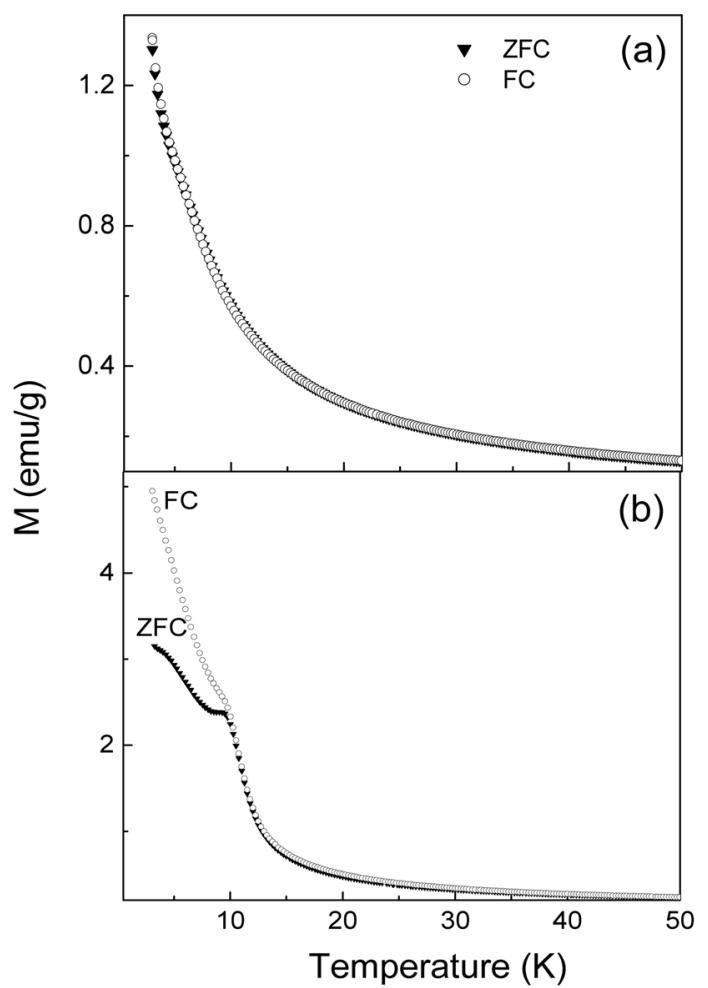

Fig. 5. FC and ZFC vs. temperature of the samples synthesized using the (a) water and (b) formamide solvent.

(Fig. 5a), which means that the magnetic property is similar to that of the bulk sample. However, as shown in Fig. 5b, there is a divergence between the field cooled (FC) and zero field cooled (ZFC) magnetization curves for the "formamide" sample at $11 \mathrm{~K}$, i.e., well below the Currie temperature, indicating that nanoparticles in the "formamide" sample are single domain superparamagnets with a blocking temperature of $11 \mathrm{~K}$. The ZFC curve of the "formamide" sample shows a local maximum at $11 \mathrm{~K}$, which indicates the blocking temperature $\left(\mathrm{T}_{\mathrm{B}}\right)$ of the nanoparticles with a mean volume. The FC curve increases with a decreasing temperature and never reaches saturation. This indicates that, even at the lowest temperature measured, a fraction of the particles is still in the superparamagnetic state. From a magneitc measurement of $\mathrm{Ni}_{3}\left[\mathrm{Cr}(\mathrm{CN})_{6}\right]_{2}$ nanocubes, Mallah et al. [13] have confirmed that these nanoparticles behaved similarly to the bulk material at a high temperature. The increase in the $\mathrm{FC}$ values with decreasing temperatures and the maximum peak in the ZFC magnetization are indications of cluster spin-glass [14]. In a simple description specific to our samples, the cluster spin-glass state contains disordered interacting clusters, and each cluster consists of ferrimagnetically ordered $\mathrm{Fe}^{3+}(\mathrm{LS}, \mathrm{S}=1 / 2)$ and $\mathrm{Mn}^{2+}(\mathrm{HS}$, $\mathrm{S}=5 / 2$ ) regions.

For PB analogs, the Curie temperature $T \mathrm{C}$ is expressed 


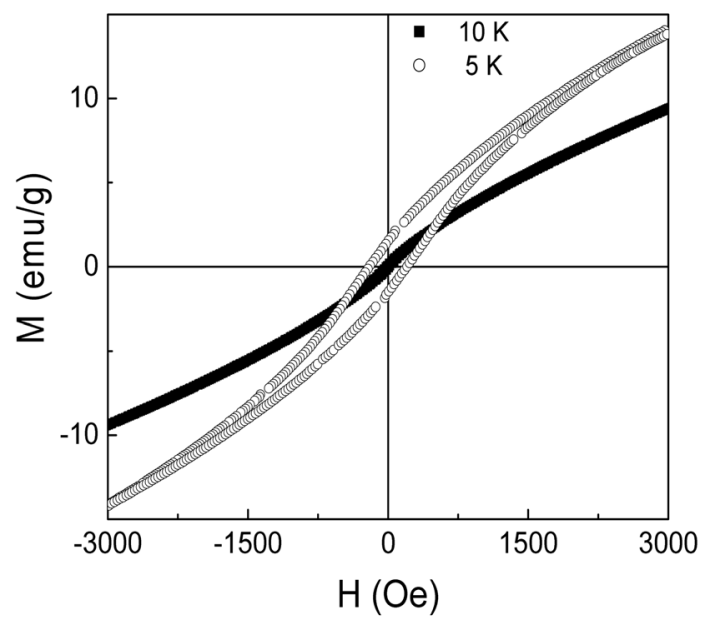

Fig. 6. Magnetic hysteresis loop measured at $5 \mathrm{~K}$ and $10 \mathrm{~K}$ of the sample synthesized using the formamide solvent.

as in Ref. [15],

$$
\mathrm{T}_{\mathrm{c}}=\left[2\left(\mathrm{Z}_{\mathrm{ij}} \mathrm{Z}_{\mathrm{ji}}\right)^{1 / 2} \mid \mathrm{J}_{\mathrm{ij}} / / 3 \mathrm{k}_{\mathrm{B}}\right]\left[\mathrm{S}_{\mathrm{i}}\left(\mathrm{S}_{\mathrm{i}}+1\right) \mathrm{S}_{\mathrm{j}}\left(\mathrm{S}_{\mathrm{j}}+1\right)\right]^{1 / 2},
$$

where $\mathrm{i}=\mathrm{j}=\mathrm{Fe}^{3+}, \mathrm{S}_{\mathrm{i}}=\mathrm{S}_{\mathrm{j}}=5 / 2, Z_{\mathrm{ij}}$ or $\mathrm{Z}_{\mathrm{ji}}$ is the number of the nearest-neighbor $\mathrm{i}(\mathrm{j})$-site ions surrounding a $\mathrm{j}(\mathrm{i})$-site ion, $\mathrm{k}_{\mathrm{B}}$ is the Boltzmann constant, and $\mathrm{J}$ is the magnetic interaction constant. As the lattice parameter of nanosized crystals does not change, we assume that the magnetic interaction constant $\mathrm{J}_{\mathrm{ij}}$ between the $\mathrm{Fe}^{3+}$ ions of the PB nanoparticle in the "formamide" sample is almost the same as that of the bulk sample. Therefore, the decrease in the Curie temperature $T_{C}$ of the $P B$ nanoparticle is perhaps due to the diminution of the average number of nearest magnetic interaction neighbors in the PB particle in comparison with the perfect crystal structure. Furthermore, defects could be present on the surface or inside of the Prussian blue particle, which may also affect the $T_{C}$.

We investigated in further detail the magnetic property of the nano-sized PB particle sample "formamide" below $11 \mathrm{~K}$. Fig. 6 presents the magnetic hysteresis loop of the "formamide" sample measured at $5 \mathrm{~K}$ and $10 \mathrm{~K}$. At $5 \mathrm{~K}$ the coercive field $\left(\mathrm{H}_{\mathrm{c}}\right)$ was $200 \mathrm{Oe}$, whereas at $10 \mathrm{~K}, \mathrm{H}_{\mathrm{c}}$ is almost 0 . This clearly shows that the "formamide" sample is superparamagnetic and that it exhibits a soft magnetic property.

\section{Conclusion}

In this work, it is shown that the Prussian blue (PB) nanoparticle samples exhibit significantly different optical and magnetic properties than those of the bulk PB samples. We have developed a new approach for the growth of $\mathrm{Na}_{x} \mathrm{Mn}_{y}\left[\mathrm{Fe}(\mathrm{CN})_{6}\right]$ nanoparticle samples using the formamide solvent, and the physical properties have been measured and compared with those of the large particle PB sample. The UV-vis absorption spectra of the samples show a broad intervalence charge-transfer band from $\mathrm{Mn}^{\mathrm{II}}$ to $\mathrm{Fe}^{\mathrm{III}}$ in the visible region between 400 and $700 \mathrm{~nm}$, and the absorption decreases abruptly in the green region for the nanoparticle PB sample. A divergence between the field cooled (FC) and zero field cooled (ZFC) magnetization curves is observed for the nanoparticle PB sample at $11 \mathrm{~K}$, indicating that nanoparticles in the sample are single domain superparamagnets with a blocking temperature of $11 \mathrm{~K}$. The increase in the FC values with decreasing temperatures and the maximum peak in the ZFC magnetization are indications of cluster spin-glass behavior.

\section{Acknowledgments}

The present research was supported in part by the National Basic Research Program of Vietnam and the Korea Science and Engineering Foundation Grant R112008-053-03001-0.

\section{References}

[1] Y. Jo, M. H. Jung, M. C. Kyum, K. H. Park, and Y. N. Kim, J. Magnetics 11(4), 160 (2006).

[2] Y. Jo, M. H. Jung, M. C. Kyum, K. H. Park, and Y. N. Kim, J. Magnetics 11(4), 156 (2006).

[3] H. Sakuma, H. Aoshima, and K. Ishii, J. Magnetics 11(3), 103 (2006).

[4] P. H. Zhou, D. S. Xue, H. Q. Luo, and X. G. Chen, Nano Lett. 2 845-847 (2002).

[5] P. A. Berseth, J. J. Sokol, M. P. Shores, J. L. Heinrich, and J. R. Long, J. Am. Chem. Soc. 122, 9655-9662 (2000).

[6] M. Pyrasch, A. Toutianoush, W. Q. Jin, J. Schnepf, and B. Tieke, Chem. Mater. 15, 245-254 (2003).

[7] D. Moscone, D. D’Ottavi, D. Compagnone, G. Palleschi, and A. Amine, Anal. Chem. 73, 2529-2535 (2001).

[8] J. T. Culp, J. H. Park, D. Stratakis, M. W. Meisel, and D. R. Talham, J. Am. Chem. Soc. 124, 10083-10090 (2002).

[9] V. Vien, N. V. Minh, H. I. Lee, J. M. Kim, Y. Kim, and S. J. Kim, Mater. Chem. and Phys. 107, 6-8 (2008).

[10] L. V. Azaroff, Elements of X-ray Crystallography, McGrawHill, New York, 1968.

[11] H. Tokoro, S. Ohkoshi, T. Matsuda, and K. Hashimoto, Inorg. Chem. 43, 5231-5236 (2004).

[12] M. Fox, Optical Properties of Solids, Oxford University Press 115-130 (2001).

[13] T. Mallah, S. Thiebaut, M. Verdaguer, and P. Veillet, Science 262, 1554-1557 (1993).

[14] J. A. Mydosh, Spin Glasses, Taylor \& Francis, Washington DC (1993).

[15] S. Ohkoshi, T. Iyoda, A. Fujishima, and K. Hashimoto, Phys. Rev. B 56, 11642-22652 (1997). 